\title{
Amino acids necessary for DNA contact and dimerization imply novel motifs in the papillomavirus E2 trans-activator
}

\author{
S.S. Prakash, ${ }^{1,2}$ Steven R. Grossman, ${ }^{2-4}$ R. Blake Pepinsky, ${ }^{5}$ Laimonis A. Laimins, ${ }^{6}$ \\ and Elliot J. Androphy $1,7,8$ \\ ${ }^{1}$ Department of Dermatology, New England Medical Center and Tufts University School of Medicine, Boston, \\ Massachusetts 02111 USA; $^{3}$ Pritzker School of Medicine, University of Chicago, Chicago, Illinois 60637 USA; ${ }^{5} \mathrm{Biogen}$, Inc., \\ Cambridge, Massachusetts 02142 USA; ${ }^{6}$ Howard Hughes Medical Institute and Department of Molecular Genetics and Cell \\ Biology, University of Chicago, Chicago, Illinois 60637 USA; $^{7}$ Department of Molecular Biology and Microbiology, Tufts \\ University School of Medicine, Boston, Massachusetts 02111 USA
}

The bovine papillomavirus E2 protein regulates viral transcription by binding as a dimer to the DNA sequence ACCGN $_{4}$ CGGT. The dimerization and DNA-binding properties are localized within its carboxy-terminal 85 amino acids (325-410). Utilizing random mutagenesis coupled with phenotypic selection in yeast, functionally important amino acids in the DNA-binding domain were identified. Four trans-activation defective point mutants within a short segment (amino acids 337-344) were DNA binding defective but dimeric. The mutation of a conserved tryptophan to serine also eliminated DNA binding, but loss of dimerization was implicated because addition of dimeric monoclonal antibody complemented this defect. A simple assay for E2 dimerization was developed using UV irradiation to produce an interchain cross-link within a dimer. No heterodimeric complexes were formed when pools of $\mathrm{E} 2$ of varying lengths were mixed, and only proteins with tryptophan at position 360 could be UV cross-linked. Peptide mapping of irradiated E2 protein localized the cross-link to an 18-amino-acid region bracketing this tryptophan. Substitutions for this tryptophan demonstrated the requirement for a hydrophobic residue at this position, but surprisingly, even alanine was functional. Replacement of this tryptophan with three polar amino acids or glycine eliminated DNA-binding activity, but addition of dimeric monoclonal antibody restored this function. The amino acids that were identified as being involved in DNA contact and dimerization imply that these functions are mediated by novel binding motifs.

[Key Words: Papillomavirus E2 protein; DNA-binding protein; dimerization; transcription factor; gene expression]

Received October 1, 1991; revised version accepted November 25, 1991.

The E2 trans-activator of bovine papillomavirus (BPV) type 1 provides an interesting model for a possible new type of DNA-binding and dimerization motif. This 410amino-acid protein is responsible for the coordination of BPV transcription. E2 binds specifically and with high affinity to the palindrome ACCGN ${ }_{4}$ CGGT (Androphy et al. 1987; Moskaluk and Bastia 1988; Li et al. 1989; Monini et al. 1991) and activates transcription from promoters with these enhancer elements (Spalholz et al. 1985; Harrison et al. 1987; Haugen et al. 1987; Hirochika et al. 1987; Spalholz et al. 1987; Gius et al. 1988; HawleyNelson et al. 1988; Moskaluk and Bastia 1988; Li et al. 1989; Sousa et al. 1990). Genetic studies predict that the

\footnotetext{
${ }^{2}$ These authors contributed equally to this work. ${ }^{4}$ Present address: Department of Medicine, Brigham and Women's Hospital, Boston, Massachusetts 02115 USA.

${ }^{8}$ Corresponding author.
}

E2 gene product, similar to other transcription factors, is composed of discrete, function-specific modules. Its carboxyl terminus represents the domain responsible for specific DNA binding and protein dimerization (Dostatni et al. 1988; Giri and Yaniv 1988; Haugen et al. 1988; McBride et al. 1988, 1989; Knight et al. 1991; Monini et al. 1991). The amino terminus of E2 (amino acids $1-220$ ) is the trans-activation domain and is believed to belong to the amphipathic helix class of transcription factors (Giri and Yaniv 1988; Haugen et al. 1988; McBride et al. 1989). Like these acidic activators, E2 functions are operative in Saccharomyces cerevisiae (Lambert et al. 1989; Morrissey et al. 1989; Stanway et al. 1989|. The DNA-binding/dimerization and trans-activation domains are separated by a poorly conserved sequence that is $\sim 100$ amino acids in BPV.

DNA-binding proteins usually interact with DNA in a dimeric form (Ptashne 1988). Consistent with this obser- 
vation, the DNA targets of such dimeric proteins are often palindromic, reflecting the twofold symmetry of the dimer. For many of these proteins, structural domains or motifs have been characterized that mediate dimer interactions. Examples include leucine zipper, helix-loop-helix, and helix-span-helix proteins (Landschulz et al. 1988; Mitchell and Tjian 1989; Williams and Tjian 1991). Comparison of the amino acid sequences of human and animal E2 proteins reveals segments of high homology (Giri and Yaniv 1988), but the E2 DNA-binding domain bears no obvious similarities to that of other eukaryotic transcription factors. Several studies have demonstrated that E2 binds DNA as a dimer (Dostatni et al. 1988; Haugen et al. 1988; Moskaluk and Bastia 1989). For example, McBride et al. (1989) suggested that the E2 DNA-binding domain existed as a stable dimer in solution using an electrophoretic mobility-shift assay (EMSA) in which $5 \mathrm{~m}$ urea was necessary to allow subunit mixing and heterodimer formation between different sized E2 proteins. These studies, however, did not address the oligomeric state of the protein in the absence of DNA. Recently, through sedimentation studies, Knight et al. (1991) have shown that the full-length E2 protein formed a dimer in solution. Nonetheless, the amino acids that mediate dimerization have not been identified.

Because the constitution of the DNA interaction site and dimerization region could not be surmised, an unbiased method was preferable for identifying the amino acids responsible for these functions. Therefore, we utilized a protocol to randomly generate and functionally isolate transcriptionally defective carboxy-terminal E2 mutations. These mutants were examined in vitro for the ability to specifically bind the E2 DNA motif by EMSA and the ability to dimerize by UV light-induced peptide-peptide cross-linking assay. We propose that the E2 DNA recognition function is mediated by a novel motif consisting of alternating hydrophobic and positively charged amino acids and that tryptophan residues serve as a contact point between E2 monomers.

\section{Results}

Random mutagenesis distinguishes amino acids required for DNA contact from dimerization

To delineate specific amino acids responsible for either contacting nucleic acid and/or dimer formation, we designed an experimental protocol that employed chemical mutagenesis (Myers et al. 1985) and a yeast-based screen to isolate forms of $\mathrm{E} 2$ that were defective for stimulation of a promoter containing four E2-binding sites upstream of the $\beta$-galactosidase gene (Morrissey et al. 1989). Yeast colonies that failed to turn deep blue after replica-plating on galactose/X-gal plates were selected for further investigation. By design, coding mutations were limited to the carboxy-terminal third of E2, from amino acid 286 to 410 [the mutagenized portion was between nucleotides 3455 (KpnI) and 3881 (BstXI); amino acid 410 is nucleotide
3837]. In the initial screen, $20 \mathrm{E} 2$ missense mutations were isolated.

Four point mutants (333-V, 337-L, 339-M, and 344-L; the number refers to the position of the mutant in the BPV E2 protein; the letter signifies the resultant amino acid mutation) were clustered over a 12-amino-acid span from position 333 to 344 . This segment represents the most highly conserved portion of the E2 DNA-binding domain among the animal and human papillomaviruses (Fig. 1). These point mutations were derived from white colonies and, after isolation and sequencing, were confirmed to be trans-activation defective with either one, two, or four E2-responsive elements (Table 1). Extracts from these yeast strains failed to alter the mobility of E2 DNA elements by EMSA (data not shown). Similar results were reproduced after each mutant was synthesized in bacteria in the 127-amino-acid truncated form (Fig. 2A).

Because it was possible that the mutant E2 proteins were DNA binding defective owing to failure to dimerize, their ability to form stable homodimers was therefore evaluated by utilizing the UV cross-linking assay described in detail below. Both as full-length E2 proteins expressed in $S$. cerevisiae and as truncated peptides synthesized in Escherichia coli, mutants 337-L, 339-M, and 344-L existed as preformed dimers (Fig. 2C). None of the other mutants isolated in the targeted portion of E2 (amino acids 286-410) exhibited this DNA-binding-defective, dimerization-competent phenotype. These data suggested that the peptide region between amino acid 337 and 344 was required for stable and specific interactions with DNA. Under similar conditions, UV crosslinked dimers were not detectable with the mutation of glycine-333 to valine (V) (Fig. 2C) whether expressed in full-length form in yeast or as a purified peptide from bacterial vectors.

Mutant 333-V was characterized further utilizing a "super" mobility-shift assay in which the B202 monoclonal antibody (Mohr et al. 1990) or affinity-purified rabbit anti-E2 antibody (Androphy et al. 1987; Hubbert et al. 1988) was added to the extract. In this system the antibody can provide a bridge that holds monomers together, thereby allowing the DNA contact region to stably bind the probe. With this artificial dimerization sig-

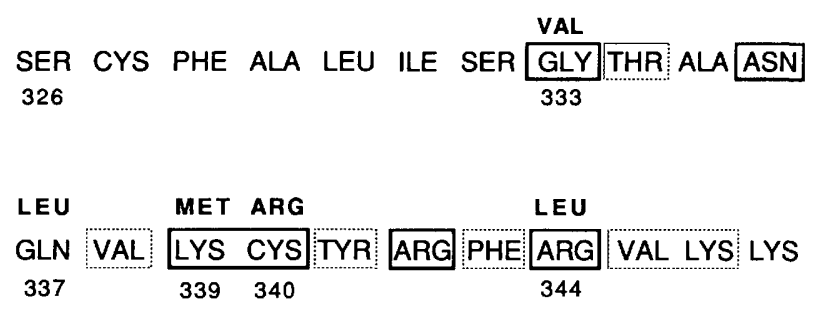

Figure 1. The wild-type BPV E2 peptide sequence in the DNA contact region is depicted with mutations in boldface type above the altered residues. The numbers below each amino acid denote their positions in the E2 protein. Solid- and broken-line boxes represent conserved and semiconserved amino acids among the papillomavirus E2 proteins, respectively. 
Table 1. Trans-activation by E2 DNA-binding domain mutants in S. cerevisiae

\begin{tabular}{|c|c|c|c|c|}
\hline \multirow[b]{2}{*}{ E2 mutant } & \multirow{2}{*}{$\begin{array}{l}\text { Amino acids in } \\
\text { wild type }\end{array}$} & \multicolumn{3}{|c|}{$\begin{array}{l}\text { Number of E2-binding } \\
\text { sites in promoter }\end{array}$} \\
\hline & & 1 & 2 & 4 \\
\hline $333-\mathrm{V}$ & G & 0 & 0 & 0 \\
\hline $337-\mathrm{L}$ & $\mathrm{Q}$ & 0 & 0 & 0 \\
\hline 339-M & $\mathrm{K}$ & 0 & 0 & 0 \\
\hline $340-R$ & $\mathrm{C}$ & 0 & 0 & 0 \\
\hline $344-\mathrm{L}$ & $\mathbf{R}$ & 0 & 0 & 0 \\
\hline 349/73-LL & $349-\mathrm{H}_{;} 373 \mathrm{Q}$ & 0 & $3+$ & $5+$ \\
\hline $360-S$ & W & 0 & 0 & $5+$ \\
\hline 3-YLV & $366-N ; 376-I ; 398-G$ & 0 & $4+$ & $5+$ \\
\hline 3-SLI & 374-A;375Q; 391-K & 0 & 0 & $4+$ \\
\hline 386-W & $\mathrm{R}$ & $2+$ & $4+$ & $6+$ \\
\hline 399-I & M & $1+$ & $6+$ & $7+$ \\
\hline $402^{*}$ & 4-amino-acid insert & 0 & 0 & 0 \\
\hline $408-410^{\star}$ & * & $1+$ & $3+$ & $5+$ \\
\hline $411^{\star}$ & * & $1+$ & $4+$ & $4+$ \\
\hline Bcl-del & * & 0 & 0 & 0 \\
\hline \multicolumn{5}{|l|}{ pY-E2 (wild } \\
\hline type) & & $4+$ & $7+$ & $8+$ \\
\hline
\end{tabular}

Trans-activation was assayed in yeast containing a $\beta$-galactosidase reporter plasmid with one, two, or four E2-binding-sitedependent promoters (Morrissey et al. 1989). Yeast cells were plated on selective minimal medium containing $100 \mathrm{~mm}$ potassium phosphate $(\mathrm{pH} 6.9), 2 \%$ galactose, and $0.004 \% \mathrm{X}$-gal and incubated at $30^{\circ} \mathrm{C}$ for $48 \mathrm{hr}$ before visually reading five independent colonies for each mutant, all plated simultaneously, and assessing the blue color on a linear scale of $1-8$. This assay allowed reproducible quantitation of low degrees of trans-activation $(1-2+)$ that were not detectable with the ONPG colorimetric assay (Morrissey et al. 1989) but underestimated high levels of activation (7-8+). Activities were comparable to levels detected in liquid media for higher expressing mutants. 402 * has an in-frame 4-amino-acid insert (Haugen et al. 1988). A frameshift in $408-410^{*}$ replaced these 3 amino acids (LDF) with 11 amino acids (TSDHCHCLFFI). $411^{*}$ changed the translation termination codon TAA to TTA $(F)$ and resulted in the addition of 24 amino acids to the protein. Bcl-del has a deletion of the $B c I$ fragment and loss of the codons for amino acids 379-410.

nal, E2-333-V synthesized in yeast and bacteria remained unable to recognize the E2-binding-site probes (data not shown), in contrast to other mutations whose DNA binding could be specifically restored by these antibodies (see below).

Having identified the 333-344 region as essential for DNA binding, homology searches of the GenBank data base revealed no significant sequence similarity of this region to sequences in other DNA-binding proteins. Cysteine-340 in BPV E2 (see Fig. 1) is found in this segment in all papillomavirus $\mathrm{E} 2$ proteins. When the $\mathrm{C}-340$ codon was converted to arginine $(R)$ using site-directed mutagenesis (Kunkel et al. 1987), the mutant failed to stimulate the series of yeast E2-dependent promoters (Table 1), was unable to form a stable complex with E2-binding sites by EMSA (Fig. 2A), and was present as dimers using the UV cross-linking assay (Fig. 2B), thus being pheno- typically similar to the mutants in the surrounding region described above.

Random mutagenesis implies the importance of tryptophan-360 for dimerization

In contrast to the E2 mutants which were completely defective for trans-activation of the E2 promoter in yeast, other mutations isolated from light blue colonies were only partially defective. When analyzed further with one, two, or four E2-binding sites, a pattern was apparent: While most mutations were unable to stimulate or slightly stimulate one or two E2 elements, respectively, all were partially trans-activation competent with four E2 motifs (Table 1). By DNA sequencing, one point mutation was found to convert tryptophan (W)-360 to serine. This amino acid is found at the analogous position in all human and animal papillomavirus E2 proteins. When expressed in yeast, E2-360-S failed to alter mobility of the E2 probe by EMSA (Fig. 3A). However, longer exposures demonstrated that $\sim 5 \%$ of the probe was shifted with four E2 motifs. Similar results were found when E2-360-S was purified from bacterial vectors (data not shown). With high concentrations of E2 protein and reduced nonspecific competitor DNA concentration, weak interactions with a one-binding-site probe were detected by EMSA (data not shown).

\section{Antibody-restored DNA binding to E2-360-S in a supershift assay}

To distinguish the contributions of a deficit in DNA recognition from dimerization in the overall inability of E2360-S to bind DNA stably, we attempted to complement the potential loss of dimerization with exogenously added E2 monoclonal antibody and thus restore DNAbinding activity. Addition of mAb B202 (IgG 2a) to wildtype E2 yeast extracts followed by EMSA resulted in the formation of a slower migrating complex (supershift), indicating that the antibody did not interfere with DNA binding. Addition of B202 to E2-360-S yeast extracts induced high-affinity DNA binding with a supershifted complex observed with two or four E2-binding sites but not with a single-binding-site probe (Fig. 3B). Interestingly, the 360-S-B202 complex migrated slightly faster than the wild-type complex on the two-binding-site probe which, in view of the inability of a single E2-binding site probe to supershift, suggested that one monoclonal antibody was holding two monomers across two halfsites. Similar aberrant mobilities were observed with the four E2 DNA-site motif (Fig. 3B).

These results implied that mAb B202 efficiently provided a dimerization function that allowed E2-360-S to bind DNA stably in the mobility-shift assay. Another monoclonal antibody (B201, IgG 2b), whose epitope maps at least 100 amino acids farther amino-terminal from the DNA-binding domain than B202, was also able to complement the DNA-binding defect of E2-360-S but was much less efficient (data not shown). In further support for the hypothesis that the heterologous dimeriza- 
A

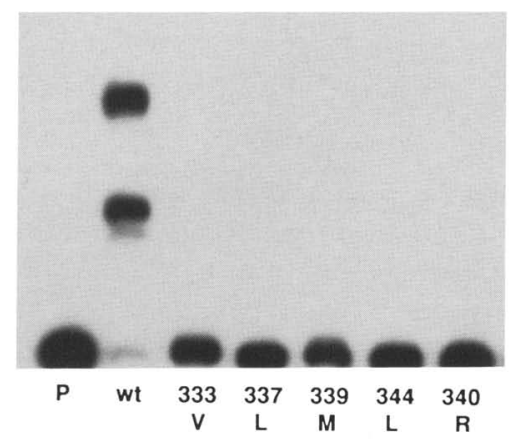

B

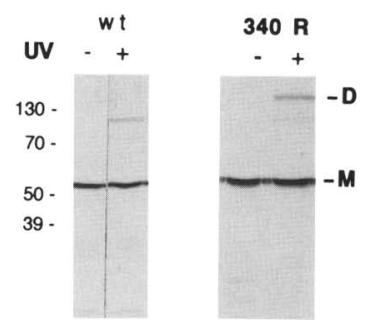

C

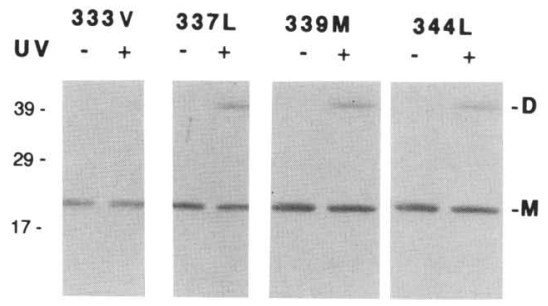

Figure 2. Characterization of DNA-binding-defective mutants. (A) Analysis of the DNA-binding capability of E2 mutants by mobility-shift assay. Proteins were partially purified 127-amino-acid carboxy-terminal peptides (amino acids 286-410) from E. coli. The probe $(P)$ is the ${ }^{32}$ P-end-labeled 114-bp NsiI fragment with two E2-binding motifs from pBY-2 (Morrissey et al. 1989). Equivalent, nonsaturating quantities of $\mathrm{E} 2$ peptides as assessed by immunoblot were incubated for $30 \mathrm{~min}$ at $4^{\circ} \mathrm{C}$ with $1 \mathrm{ng}$ of probe $(10,000$ $\mathrm{cpm} /$ reaction) along with carrier DNA. The DNA-protein complexes were resolved by electrophoresis in $5 \%$ polyacrylamide gels in $0.5 \times \mathrm{TBE}$ at $150 \mathrm{~V}$. (wt) Wild-type. The middle and upper band shifts represent loading of one or two E2 dimers onto the probe, respectively. $(B, C)$ UV-induced dimerization of E2 proteins. $(B)$ Crude yeast extracts containing wild-type E2 and E2-340-R proteins were UV irradiated (UV +) and detected by immunoblot using anti-E2 sera. E2 peptides not cross-linked remained as $50-\mathrm{kD}$ monomers $(\mathrm{M})$; the fraction that was covalently cross linked migrated as a $100-\mathrm{kD}$ band (D). (C) UV dimer analysis of 127 -amino-acid E. coli-synthesized proteins from four phenotypically selected mutants.

tion signal provided by mAb B202 induced binding to DNA by E2-360-S, Fab and $\mathrm{F}(\mathrm{ab})_{2}$ fragments of $\mathrm{B} 202$ were isolated and tested in the supershift assay. The addition of both $\mathrm{Fab}$ and $\mathrm{F}(\mathrm{ab})_{2}$ to the reaction reduced the mobility of wild-type E2 DNA complexes as predicted, whereas the $F(a b)_{2}$, but not the Fab, fragments restored DNA binding to yeast extracts of E2-360-S /data not shown). This excluded the possibility that binding of B202 to E2-360-S induced a conformational change that exposed its DNA recognition domain. In summary, the ability of a dimeric antibody, but not its Fab fragments, to induce DNA binding indicated that the $360-\mathrm{S}$ muta- tion altered the dimerization properties of the E2 DNAbinding domain.

Essentially similar results were found utilizing E2$360-\mathrm{S}$ protein purified from bacteria. To perform the supershift assay, 360-S was synthesized in the 127-aminoacid form, as shorter peptides are not recognized efficiently by B202. The only difference noted was that in contrast to the full-length protein, the truncated form of this E2 mutant was able to bind a single E2 DNA motif when the EMSA reaction was supplemented with B202 (data not shown). From this, we inferred that the smaller E2 monomers can be positioned closer together by the
Figure 3. Monoclonal antibody complements the dimerization defect and restores DNA binding. $(A)$ Yeast extracts of E2360-S (lanes $S$ ) or wild-type E2 (lanes $W$ ) were added to a probe with one, two, or four E2-binding-sites, and complexes were identified by mobility-shift assay. The carat at left indicates the mobility of the free probe that was not bound by E2-360$\mathrm{S}$. The same extracts were used in $B$, but $\mathrm{mAb}$ B202 was added to the reaction (super shift assay). Lanes $P$ represent the mobility of the probe without $\mathrm{E} 2$ protein. Addition of the monoclonal antibody resulted in formation of a slowly migrating complex with the E2-360-S extract as well as the wild-type E2. A 5\% acrylamide gel was used for $A$; a $4 \%$ acrylamide gel was used for $B$.
A

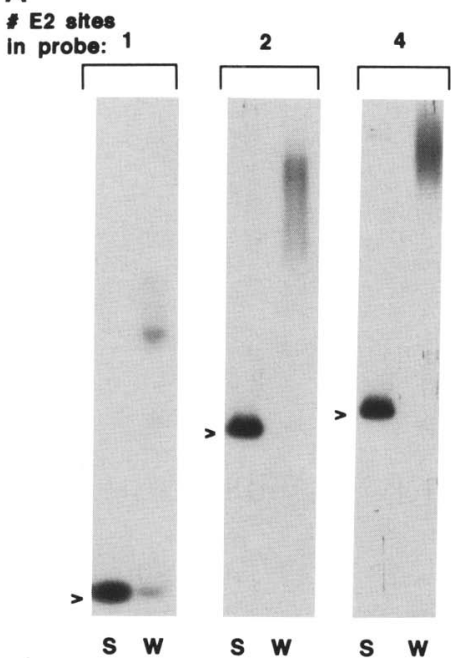

B

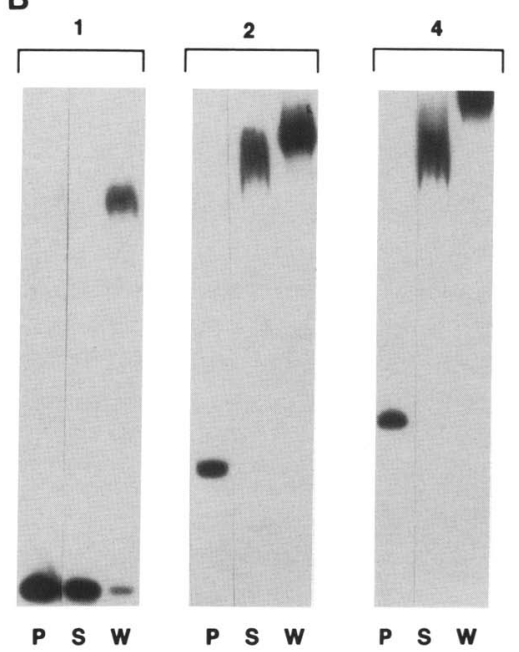


monoclonal antibody on the probe, whereas the 410amino-acid E2 monomers cannot.

\section{Dimerization state of E2-360-S}

Although the supershift experiments provided support that the defect in 360-S was in its ability to dimerize, we were curious as to the relative contributions of changes in association versus dissociation rates to the overall dimerization affinity. A subunit mixing experiment was therefore performed to assess the rapidity of mixing of different sized wild-type or 360-S proteins under native conditions. As stated previously, at high E2-360-S concentrations with reduced poly[d(I-C)] concentrations, complexes were detected by EMSA in the absence of added mAb B202. Mixing of wild-type 127- and 87amino-acid peptides prior to analysis by EMSA normally leads to very little heterodimer formation, even after $2 \mathrm{hr}$ of incubation, owing to the stability of the E2 dimers (Fig. 4, lanes 2-4). In contrast, mixing of the $87-$ and 127-residue 360 -S proteins led to stoichiometric formation of heterodimers in approximately the $1: 2: 1$ ratio expected for freely mixing subunits (Fig. 4, lanes 5-7). Although the ability to free-mix indicated that the $360-\mathrm{S}$ dimers must be very short relative to wild type, we could not quantitate association rates, owing to the need for urea denaturation/renaturation to detect the association of wild-type E2 monomers.

The ability of full-length E2-360-S to dimerize was also evaluated by exposing extracts to UV radiation (see below). Immunoblots of these extracts revealed only the $50-\mathrm{kD}$ monomeric E2 peptide. This result was reproduced with bacterially produced E2-360-S in the 127and 87-amino-acid truncated forms. However, the lack of photoreactivity was probably the result of the loss of this unique tryptophan, as suggested by other studies (see

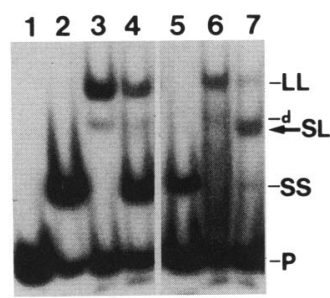

Figure 4. The 360-S mutation leads to a reduced dimer lifetime. Wild-type E2 or E2-360-S proteins of 87 and 127 amino acids were mixed and analyzed by mobility-shift assay for heterodimer formation. For E2-360-S proteins, high protein concentrations $\left(>5 \times 10^{-7} \mathrm{M}\right)$ with reduced nonspecific competitor allowed the formation of complexes. Concentrations of wildtype proteins were $1 \times 10^{-7} \mathrm{M}(\mathrm{E} 2 / 87)$ and $5 \times 10^{-8} \mathrm{M}(\mathrm{E} 2 / 127)$. The probe was $1 \mathrm{ng}$ of a 37-bp, one-E2-binding-site oligonucleotide, end-labeled with Klenow and ${ }^{32} \mathrm{P}$-labeled dCTP. (Lane 1) 37-bp probe; (lane 2) E2/87; (lane 3) E2/127; (lane 4) E2/87 + E2/ 127 incubated for $2 \mathrm{hr}$ prior to addition of probe and assay; (lane 5) E2-360-S/87; (lane 6) E2-360-S/127; (lane 7) E2-360-S/ $87+360-\mathrm{S} / 127$ incubated $1 \mathrm{~min}$ prior to assay. (P) Probe; (SS) E2/87 homodimer; (SL) E2/87-E2/127 heterodimer; (d) E2/127 proteolytic degradation product; (LL) E2/127 homodimer. below). To address this further, bacterially expressed wild-type and 360-S mutant peptides of different sizes were mixed with and without urea denaturation and subsequent UV radiation. Under these conditions, only the wild-type homodimer was covalently cross-linked (data not shown), and heterodimers, if existent, did not covalently couple. This result implied that a potential dimer with a single reactive tryptophan could not form the stable cross-linked product.

\section{Other mutations in E2 that affect dimerization}

In screening, other mutants that were trans-activation defective (Table 1) were found to dimerize as evaluated by UV cross-linking, although the proportion of protein that was covalently coupled was generally reduced. In addition, all mutants altered the mobility of the E2-binding-site probes by EMSA, although again with reduced efficiency; and in several instances, the DNA-binding capability improved with addition of the monoclonal antibody.

Because W-360 was believed to be a dimer contact point, we asked whether the peptide sequences carboxyterminal to W-360 were also required for DNA binding and dimerization. Earlier studies have indicated that the full reading frame is required for E2 trans-activation. To analyze biochemically the function of the E2 carboxyl terminus, we inserted a three-frame translational termination linker in the $B c l$ site, eliminating amino acids 379-410 from the protein. This E2 deletion (Bcl-del) was transcriptionally inactive in yeast (Table 1). Because this deletion did not bind DNA by supershift and was not cross-linked by UV light (data not shown), we inferred that sequences in the carboxyl terminus are required for proper folding and function of both the DNA contact and dimerization regions. An E2-jun chimera (E2-Bcl-jun) in which the c-jun leucine zipper was inserted in-frame into the $B c I$ site at nucleotide 3736 did not trans-activate the E2-dependent promoter in full-length form in yeast or bind DNA when isolated from bacteria (data not shown). Using polyclonal rabbit antiserum, only weak DNA binding was noted with $402^{*}$, a previously described trans-activation-defective E2 mutant with a 4-amino-acid insertion at position 402 (3812SS in Haugen et al. 1988; labeled $402^{\star}$ in this work), and no supershifted complexes were detectable with E2-333-V, E2Bcl-del, or E2-Bcl-jun (data not shown).

\section{UV light-induced cross-linking of E2: an assay for dimerization}

UV light was found to induce covalent cross-links between protein units, providing an assay for dimerization of wild-type E2. When purified E2/87 protein was irradiated briefly with shortwave $(254 \mathrm{~nm}) \mathrm{UV}$ light and the products were analyzed by SDS-PAGE (under denaturing and reducing conditions), a $20-\mathrm{kD}$ band was observed by Coomassie blue staining (not shown) and Western blot, which is consistent with it being a dimer (Fig. 5, lane 1). 


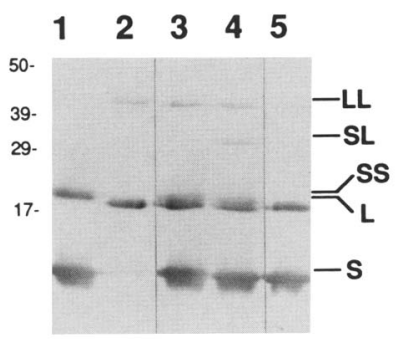

Figure 5. E2 proteins can be covalently cross-linked by UV irradiation and exist as stable dimers in solution. Mixtures of purified E2/87 and E2/143 were UV cross-linked either with or without prior exposure to $4 \mathrm{M}$ urea, separated by SDS-PAGE, and immunoblotted with E2 antibody and peroxidase detection. Heterodimers were only observed when the E2/87 and E2/143 mixture had been exposed to denaturant, indicating that carboxy-terminal truncated E2 proteins are stable long-lived dimers in solution. The concentration of E2/87 was $5 \times 10^{-8} \mathrm{M}$, and the E2/143 concentration was $2 \times 10^{-8} \mathrm{M}$. Proteins in each lane were UV irradiated with $1000 \mu \mathrm{J}$. (Lane 1) E2/87; (lane 2) $\mathrm{E} 2 / 143$; (lane 3) E2/87 + E2/143; (lane 4) E2/87 + E2/143 mixed in $4 \mathrm{M}$ urea, diluted 10-fold in PBS, and exposed to UV; (lane 5) same as lane 4 , only diluted into $4 \mathrm{M}$ urea and exposed to UV. (S) E2/87 monomer; (L) E2/143 monomer; (SS) E2/87 homodimer; (SL) E2/87/143 heterodimer; (LL) E2/143 homodimer.

Approximately $20 \%$ of the E2 protein as assayed by scanning densitometry of Coomassie blue-stained gels was converted into this form. A similar result was obtained for full-length 50-kD E2 after UV irradiation of a total cell lysate from yeast expressing the product and for crude bacterial extracts containing carboxy-terminal E2 peptides. In each instance when irradiation products were subjected to SDS-PAGE and analyzed by Western blotting with anti-E2 antibody, only monomer and covalently coupled dimeric products were detected, thus indicating the specificity of the reaction (Fig. 2B,C, respectively).

One potential explanation for the observed photochemical effects was the fortuitous induction of irreversible covalent linkages between predominantly monomeric forms of reactive E2 peptides in solution. To address this possibility, a subunit mixing experiment was performed. If E2/87 existed as a stable dimer in solution, mixing of E2/87 and the longer E2/143 under native conditions should result in very little heterodimer formation. However, under denaturing conditions, subunit mixing should occur once the denaturant is removed (McBride et al. 1989). If random interactions between monomers were the basis of the observed UV cross-linking, mixing of E2/87 and E2/143 should allow cross-linking of heterodimers without need for denaturing agent. Purified E2/87 was mixed with purified E2/143 in the presence or absence of $4 \mathrm{M}$ urea, and the solutions were subsequently diluted 10 -fold either with buffer or $4 \mathrm{M}$ urea and then irradiated with UV light. Reaction products were analyzed by SDS-PAGE followed by Western blotting. Cross-linked heterodimers were not observed after mixing under native conditions but were detected after incubation of the two proteins in $4 \mathrm{M}$ urea followed by 10 -fold dilution (Fig. 5). Thus, the most consistent explanation for the cross-linking data is that proteins containing the E2 DNA-binding domain exist as stable, long-lived (>15 $\mathrm{min}$ ) dimers in solution that are capable of being disrupted by $4 \mathrm{~m}$ urea. Dilutional analysis after urea denaturation (to enhance the rate of equilibration of monomer and dimer), followed by UV cross-linking, immunoblotting, and chemiluminescent detection for added sensitivity, yielded an approximate $K_{\mathrm{d}}$ for dimerization on the order of

$10^{-8} \mathrm{M}$ (data not shown) for the E2/87 protein.

\section{Identification of W-360 as the site of UV cross-linking}

The position of the UV-induced cross-link in E2 was examined with a combination of peptide-mapping techniques and mutagenesis. Treatment of UV cross-linked E2/87 with the lysine-specific protease endoproteinase Lys-C (Endo-Lys) revealed a complete cleavage product of $\sim 10 \mathrm{kD}$, which was slightly larger than the monomer on SDS-PAGE (Fig. 6A). The amino-terminal sequence of this peptide, as determined by automated Edman degradation, began with lysine-347, confirming that the crosslink must be carboxy-terminal to this amino acid. The cross-link was localized further by cleavage of dimers with hydroxylamine, which cuts specifically at asparagine-glycine (N-G) dipeptides (Bornstein and Balian 1977). The only N-G in E2/127 occurs at amino acids 366-367. Using mAb B202, which recognizes an epitope within the first 25 amino acids of E2/127 /amino acids 285-310), we were able to assign the identities of hydroxylamine cleavage fragments of UV cross-linked E2/127 based on their relative molecular masses on SDS-PAGE. UV-induced E2 dimers were separated on SDS-PAGE and excised, and the gel slices were exposed to hydroxylamine or control solution (Saris et al. 1983). Two cleavage fragments were observed after subsequent SDSPAGE and B202 immunoblotting with relative molecular masses of 31 and $26 \mathrm{kD}$ (Fig. 6B, lanes 3,4). Unfortunately, the E2/127 peptide has the property of running larger than its expected size, probably the result of 10 glutamate residues at its amino terminus. However, decreases of $5 \mathrm{kD}$ for each fragment cleavage corresponded well with the expected cleavage of the carboxy-terminal 45 amino acids from each monomer in the dimer, yielding one partial and one complete cleavage product. The specificity of the cleavage for the N-G sequence was confirmed by the hydroxylamine resistance of a mutant that had replaced valine for N-366 (Fig. 6B, lane 2). On the basis of these data, the position of the cross-link must be amino-terminal to N-366/G-367; and together with the Endo-Lys result, the location of the UV cross-link must lie between amino acids 347 and 366 (Fig. 6C).

Examination of the primary sequence between amino acids 347 and 366 revealed only two photoreactive residues: C-356 and W-360. C-356 cannot partake in the cross-link reaction because it can be changed to serine with no effect on UV cross-linking (S. Grossman, S.S. Prakash, and E. Androphy, unpubl.|. Moreover, HPV-16 


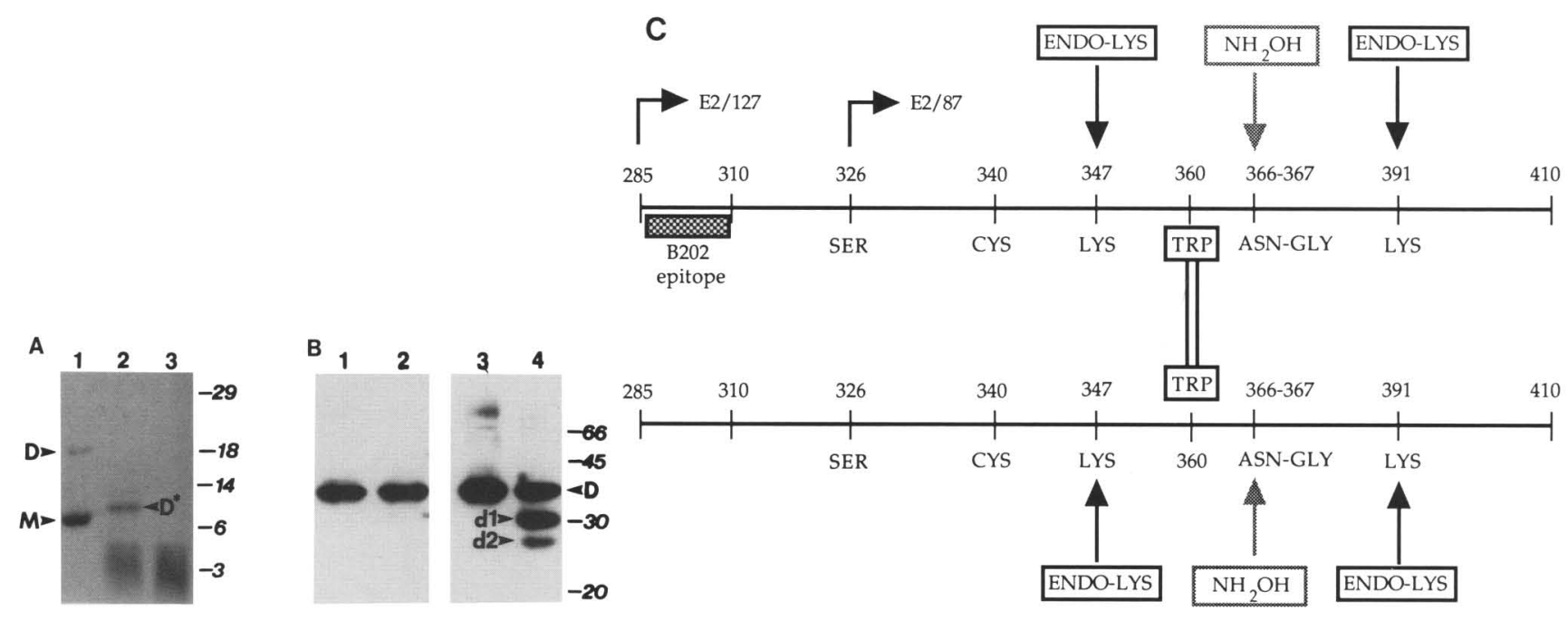

Figure 6. $(A, B)$ Mapping of the E2 UV cross-link with Endo-Lys and hydroxylamine. The position of the UV-induced peptide cross-link was narrowed to within 18 amino acids by analysis of cleavages with both endo-lys and hydroxylamine. $(A)$ Endo-lys cleavage. Purified E2/87 was UV irradiated with $1000 \mu \mathrm{J}$, incubated overnight with or without endo-lys, and electrophoresed on SDS-PAGE, and the gel was stained with Coomassie blue. A complete dimer cleavage product of $10 \mathrm{kD}(44+44$ amino acids, from lysine-347 to lysine-391) was observed. (Lane 1) UV cross-linked E2/87 without endo-lys; (lane 2) UV cross-linked E2/87 + endo-lys; (lane 3) E2/87, no UV, + endo-lys. (M) E2/87 monomer; (D) E2/87 dimer; (D*) endo-lys cleavage product of dimer. Amino-terminal sequencing confirmed that the $\mathrm{D}^{*}$ product began at lysine 347 . (B) Hydroxylamine cleavage of gel-isolated UV dimers of wild-type E2/127 or an E2/127 mutant that encoded tyrosine instead of asparagine at amino acid 366. Extracts containing either wild-type E2/127 or E2/127-366-Y were irradiated with $1000 \mu \mathrm{J}$ of UV and electrophoresed, and bands were excised at the expected dimer position. The gel slices were treated with control or hydroxylamine solution to cleave specifically at N-366 G-367. After cleavage, the gel slices were placed in the wells of a second SDS gel and immunoblotted with anti-E2 mAb B202, which recognizes an epitope in the first 25 amino acids of E2/127 (unpublished). (Lane 1) E2/127-366-Y control; (lane 2) E2/127-366-Y + hydroxylamine; (lane 3) wild-type E2/127 control; (lane 4) wild-type E2/127 + hydroxylamine. (D) 36-kD E2/127 dimer; (d1) 31-kD partial cleavage product; (d2) 26-kD complete cleavage product. $\mathrm{d} 1$ and $\mathrm{d} 2$ represent cleavage of one or both 45 -amino-acid carboxy-terminal tails from the E2/127 dimer. $(C)$ Protease cleavage of the BPV E2 DNA-binding domain localized the photochemically induced covalent cross-link between lysine-347 and asparagine-366, with cleavage sites for hydroxylamine $\left(\mathrm{NH}_{2} \mathrm{OH}\right)$ and endo-lys depicted for the carboxy-terminal 125-amino-acid E2 . The starting residues of the E2/127 and E2/87 proteins are indicated. The actual truncated proteins contain a methionine-alanine dipeptide before the first E2 residue. The epitope for mAb B202 is indicated by the stippled rectange. The vertical rectangle between the tryptophan-360 residues represents the UV-induced cross-link as predicted by these studies. The schematic is not drawn to scale and should not be interpreted as a model for the three-dimensional dimer orientation.

E2 can be UV cross-linked and does not contain cysteine at the analogous position (S. Patankar and E. Androphy, unpubl.). W-360 is therefore the most likely candidate for the UV-induced cross-link.

To further address the hypothesis that W-360 was the site of the UV cross-link, we took the genetic approach of replacing W-360 with other aromatic amino acids with lower photoreactivities and testing for both UV crosslinking and dimerization, as well as transcriptional activation in S. cerevisiae. A 360 mutant that could dimerize but could not UV cross-link would be added evidence that W-360 was involved in the UV reaction. Conservative replacement of W-360 with phenylalanine $\langle F|$ resulted in a protein with wild-type DNA-binding and yeast trans-activation activities but one that did not UV cross-link (Table 2). Although its DNA-binding activity implied intact dimerization, this function was assessed directly by chemical cross-linking with the homobifunctional reagent disuccinimidyl suberate (DSS), which reacts with free amino groups. Treatment of E2 proteins with $0.5 \mathrm{mM}$ DSS for $15 \mathrm{~min}$ resulted in the efficient cross-linking of E2 dimers (data not shown). The validity of the assay was demonstrated as with UV cross-linking by observing the necessity for urea denaturation prior to the cross-linking of heterodimers of different length E2 proteins (data not shown). DSS efficiently cross-linked E2/127-360-F to the same extent as a wild-type E2 protein (data not shown). The data summarized in Table 2 support our prediction further that the UV-induced cross-link occurred between closely opposed W-360 residues on each monomer chain.

\section{Structural requirements at position 360 for E2 activity}

The identification of W-360 as the site of the UV-induced cross-link implied that the two $\mathrm{W}-360$ residues in the dimer interact with each other. Therefore, we were interested in the structural requirements for the amino acid at position 360 as a possible means to better understand E2 dimerization. A panel of E2-360 mutants was generated by site-directed mutagenesis (Kunkel et al. 1987), changing tryptophan to tyrosine (Y), phenylalanine $(F)$, valine $(V)$, alanine $(A)$, glycine $(G)$, asparagine 
Table 2. Trans-activation, DNA-binding, and dimerization properties of E2 mutants

\begin{tabular}{|c|c|c|c|c|c|c|}
\hline \multirow[b]{2}{*}{ E2 mutant } & \multicolumn{3}{|c|}{$\begin{array}{c}\text { Trans-activation in yeast } \\
\text { (number of E2-binding sites) }\end{array}$} & \multirow{2}{*}{$\begin{array}{l}\text { DNA } \\
\text { binding } \\
\text { (EMSA) }\end{array}$} & \multirow{2}{*}{$\begin{array}{l}\text { Supershift } \\
\text { (B202) }\end{array}$} & \multirow{2}{*}{$\begin{array}{l}\text { UV } \\
\text { cross-link }\end{array}$} \\
\hline & 1 & 2 & 4 & & & \\
\hline $333-V$ & 0 & 0 & 0 & - & - & - \\
\hline $337-\mathrm{L}$ & 0 & 0 & 0 & - & - & + \\
\hline 339-M & 0 & 0 & 0 & - & - & + \\
\hline $340-\mathrm{R}$ & 0 & 0 & 0 & - & - & + \\
\hline $344-\mathrm{L}$ & 0 & 0 & 0 & - & - & + \\
\hline $360-Y$ & $4+$ & $7+$ & $8+$ & + & $1+1$ & \\
\hline $360-F$ & $4+$ & $7+$ & $8+$ & + & $1+1$ & - \\
\hline $360-A$ & $4+$ & $7+$ & $8+$ & + & $1+1$ & - \\
\hline $360-S$ & 0 & 0 & $5+$ & - & + & - \\
\hline $360-G$ & 0 & 0 & 0 & - & + & - \\
\hline $360-\mathrm{N}$ & 0 & 0 & 0 & - & + & - \\
\hline $360-\mathrm{R}$ & 0 & 0 & 0 & - & + & - \\
\hline $386-W$ & $2+$ & $4+$ & $6+$ & + & $1+1$ & + \\
\hline $360-\mathrm{S}, 386-\mathrm{W}$ & 0 & 0 & 0 & - & ND & ND \\
\hline $360-\mathrm{N}, 386-\mathrm{W}$ & 0 & 0 & 0 & - & ND & ND \\
\hline \multicolumn{7}{|l|}{ pY-E2 (wild } \\
\hline type) & $4+$ & $7+$ & $8+$ & + & $1+1$ & + \\
\hline
\end{tabular}

Summary of functional and biochemical studies of E2 proteins, including the tryptophan-360 mutations. For the supershift assay, + denotes DNA binding only with addition of the monoclonal antibody $i+1$ denotes DNA binding without the monoclonal antibody but also formed the slow migrating complex (supershift). (ND) Not done.

$(\mathrm{N})$, or arginine (R). The mutation to serine (S) was obtained through the phenotypic screen described above. All mutations were cloned into both full-length form for yeast E2-dependent trans-activation assays and the 127 residue form for in vitro analyses. All mutant $\mathrm{E} 2$ proteins were tested for DNA binding by EMSA, trans-activation of the E2 responsive reporter, and UV cross-linking. The mutants segregated into two groups on the lines of residue polarity, with hydrophobic mutants exhibiting the wild type and polar residues causing loss of E2 function (Table 2). All 360 mutants were negative for UV crosslinking (Table 2).

As might be expected, substitution of W-360 with polar residues $S, N$, or R resulted in the loss of DNA binding using crude yeast extracts. In the yeast trans-activation assay, the most polar 360-R and 360-N E2 mutants demonstrated no transcriptional activity (Table 2). This contrasted with the less polar 360-S, which activated the four E2-site promoter. E2/127-360-S, -R, and - $N$ were unable to specifically bind the E2-binding-site probes in an EMSA (data not shown). As stated above, with E2$360-S$ protein, some binding activity could be detected with a four-binding-site probe or with a one-binding-site probe at much higher protein concentrations $\mid>5 \times 10^{-7}$ $M)$ in the absence of poly[d(I-C)]. Addition of B202 to extracts of 360-N, 360-R, and 360-G (see below) allowed formation of the supershift complex (Table 2).

Unexpectedly, there was no requirement for an aromatic residue at position 360 , as any generally hydrophobic replacement resulted in wild-type trans-activation (Table 2) and in vitro DNA binding (data not shown). In particular, alanine provided only a free methyl group, yet was functionally intact. The $360-S$ substitution essentially added a polar hydroxyl to alanine and reduced activity dramatically. However, hydrophobicity was apparently necessary at this position, as replacement of the $-\mathrm{CH}_{3}$ group of alanine with $-\mathrm{H}$ (as in glycine, 360-G) led to the complete loss of E2 dimerization, DNA binding, and transcriptional activation (Table 2). As controls, conversion of $R-386$ to $W$ in the context of $360-N$ or $-R$ resulted in inactive $\mathrm{E} 2$ proteins, thus indicating the specific requirement for a hydrophobic amino acid at position 360 . The ability of hydrophobic residues to substitute for W-360 is consistent with its proposed role in mediating a hydrophobic dimer contact. However, these results are puzzling in light of the conservation of tryptophan at this position in all papillomaviruses.

\section{Discussion}

In both BPV and human papillomavirus, E2 gene products modulate and coordinate viral transcription. The full-length 410-amino-acid BPV E2 protein is an upstream transcription factor that allows its cognate DNA sequence to function as a classic enhancer element. In this study we explored the structural and functional requirements for E2 DNA recognition. Because the amino acids that mediate DNA contact as well as dimer formation had not been defined previously, our mutagenesis protocol and screen was developed to permit the unbiased isolation of E2 mutants in the carboxy-terminal DNA binding domain that were defective for trans-activation. Analysis of these mutants has provided evidence that E2 DNA contact and dimerization functions are ge- 
netically separable. Four mutants (337-L, 339-M, 340-R, and 344-L) were rendered E2 defective in sequence-specific DNA binding yet retained their ability to form E2 homodimers. In addition to this DNA-binding-defective, dimerization-competent phenotype, we have demonstrated the role of tryptophan-360 in dimerization but not directly in DNA contact. While interesting mutants such as E2-360-S demonstrated moderate transcriptional activity on repeat testing with the four-binding-site promoter, we assume that because E2 was carried on a $2 \mu$ vector, it was isolated during the initial screening from low-copy E2 segregants that expressed reduced levels of mutant protein.

The 333-344 dodecapeptide represents a segment of E2 highly conserved among all papillomaviruses (Fig. 1). Because the phenotypically isolated mutants in this region (with the exception of $333-\mathrm{V}$ ) and the inactive C-340 mutant were dimerization competent, we propose that this peptide specifically mediates at least part of the DNA sequence contacts. The 337,339 , and 344 mutations represented changes in lysine, arginine, and glutamine residues, all of which are known to be involved in proteinnucleic acid contacts. Because these DNA-binding-defective mutants existed in solution as preformed dimers, assembly on DNA cannot be required for association of E2 monomers.

The conclusion that the 333-344 region mediates DNA contact led us to compare its primary sequence with that of other DNA-binding proteins. No similarity to the helix-turn-helix, helix-loop-helix, homeo domain, zinc finger, or $\beta$-sheet classes of DNA-binding motifs was observed. This region consists of alternating hydrophobic and positively charged residues, and both Chou-Fasman and Garnier-Robson (Chou and Fasman 1978; Garnier et al. 1978) structural assessments predict that part of this region could fold as a $\beta$-strand or extended peptide (Fig. 7). This prediction holds for all papillomavirus E2 proteins sequenced to date. Although there is no primary sequence similarity between the 333-344 DNA contact region and the DNA contacting $\beta$-strand portions of the Met or Arc repressors (Rafferty et al. 1989; Breg et al. 1990), we suspect that E2 may fold similarly at its point of interaction with DNA. Although these models suggest folding as extended peptide, an $\alpha$-helical conformation is also possible as proline is absent from this region.

Surprisingly, E2 proteins with the G-333 to valine transition synthesized in yeast or bacteria could not be
UV cross-linked. These products failed to bind DNA in super mobility-shift experiments with monoclonal or polyclonal antisera (confirmed to recognize E2-333-V by immunoblot), suggesting that this glycine to valine modification also interfered with DNA recognition. G-333 is conserved at the analogous position in all papillomaviruses; hence, we predict that it is critical for proper folding of the DNA-binding domain. As depicted in Figure 7, the 4 amino acids prior to G-333 are hydrophobic, and 3 of the 4 are conserved among papillomavirus E2 proteins. This suggests that G-333 could be required as part of a turn necessary to fold these residues in such a manner as to interact with the hydrophobic amino acids in the predicted contact domain. Consistent with the model, a PCR-generated mutant E2 protein with the substitution of proline for serine-332 recognized the E2 DNA site by EMSA (data not shown). This fortuitous finding supports our contention that $\mathrm{G}-333$ mediates a critical turn in the protein that is necessary for E2 function.

It is formally possible that the E2 DNA-binding domain possesses two independent dimerization regions and that the 333-344 peptide might fold into an antiparallel $\beta$-sheet with a dimer partner and mediate both DNA recognition and dimerization. This is considered unlikely for several reasons: (1) there are no acidic residues to pair with the alternating basic amino acids in this region; (2) the data presented here demonstrate that amino acids to the carboxy-terminal side of this recognition region are required for stable dimer interactions.

For most DNA-binding proteins, dimer formation is an essential part of the binding interaction and also an important means by which binding is regulated. In this study we have investigated the genetic and biochemical requirements for E2 dimer interactions. In experiments designed to cross-link E2/87 to its DNA-binding-site, it was noted that UV irradiation reproducibly altered the mobility of the E2 protein as assayed on SDS-denaturing gels. Therefore, we attempted to directly cross-link E2 independent of nucleic acid. The significance of this photochemically induced covalent bond between E2 peptides is highlighted by the implication that there must be close molecular juxtaposition of the contact point because the reaction is zero order. Photoreactivity in proteins is generally mediated by cysteine, tryptophan, tyrosine, histidine, and phenylalanine in decreasing order of reactivity (Grossweiner et al. 1963). Peptide mapping with hydroxylamine and endo-lys revealed that the cross-link occurred between K-347 and N-366. Mutants

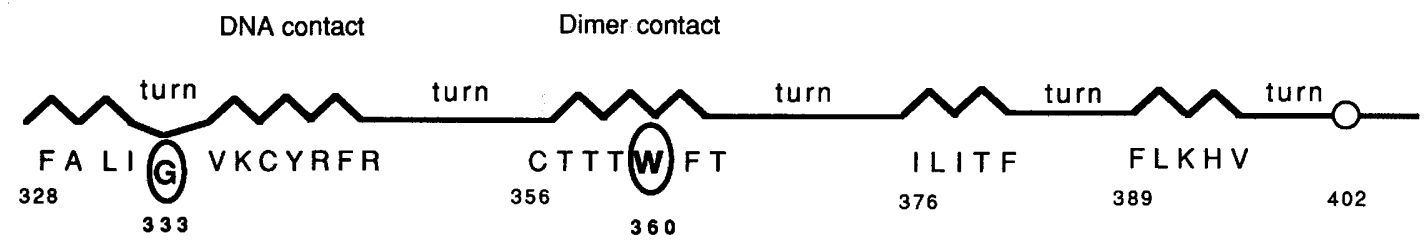

Figure 7. Model for E2 secondary structure. Chou-Fasman secondary structure predictions for each of 11 different papillomavirus E2 sequences were aligned and structures conserved in $>75 \%$ of sequences. Conserved secondary structures generally occurred at areas of high sequence homology. Sawtooth lines indicate putative $\beta$ strands. 
of W-360 that were otherwise wild type for DNA binding and dimerization (360-Y, 360-F, 360-V) were not covalently coupled by UV, strongly suggesting that the actual cross-linked residue was W-360. Photochemical alterations of aromatic amino acids such as tryptophan may occur through transient production of phenoxy, benzyl, or indolyl radicals (Grossweiner et al. 1963). UVinduced cross-linking has been demonstrated in calmodulin and is the result of bityrosine formation (Lehrer and Fasman 1967; Malencik and Anderson 1987). To directly prove that the cross-link in E2 is between two W-360 residues would require more detailed and extensive peptide mapping and would be hampered by the general low yield of tryptophan encountered during sequencing.

We observed two different types of dimerization mutants. One class, which includes the W-360 series, involved a substantial increase in the dimer $K_{\mathrm{d}}$ and decrease in half-life, although the general folding of the peptide backbone seemed to remain intact. A second class of altered E2 proteins, including 333-V and 402*, appeared to result in a disruption of protein folding and/ or dimerization. W-360 is not sufficient for dimerization because $\mathrm{Bcl}-\mathrm{del}, \mathrm{Bcl}-\mathrm{jun}$, or $402^{\star}$ retained this amino acid but failed to UV cross-link. Mutation 3-SLI was very defective in complex formation with DNA but demonstrated binding efficiency similar to that of wild type in the supershift assay (Table 2 , and data not shown). These results indicate that residues carboxy-terminal to W-360 are involved in dimer stability.

The importance of the conserved W-360 in dimer interactions was underscored further by mutagenic studies. Substitution of polar residues for W-360, including arginine, asparagine, and serine, led to defective DNAbinding phenotype that could be reversed with a crosslinking antibody. The primary defect in the $360-\mathrm{S} \mathrm{mu-}$ tant seemed to be a decreased dimer lifetime, as subunit mixing between long and short forms was immediate. In contrast, wild-type $\mathrm{E} 2$ dimers were stable with little subunit mixing evident after $2 \mathrm{hr}$. Consistent with its proposed role in dimerization, fluorescence quenching analyses indicate that $\mathrm{W}-360$ is at least partially buried in E2/87 (S. Grossman, unpubl.). The exact alignment of the opposed $\mathrm{W}$ side chains would be facilitated by a better understanding of the chemical nature of the tryptophan-tryptophan cross-link.

Interestingly, substitution of aromatic (tyrosine, phenylalanine) or hydrophobic residues (valine, alanine) for W-360 resulted in E2 proteins capable of trans-activation in yeast and, by implication, dimerization and DNA binding. The genetic analyses of the conserved W-360 residue led to the striking conclusion that any hydrophobic side chain at this position conferred dimerization capability; thus, the absolute conservation of tryptophan at this position across all species is quite intriguing. An obvious possibility is that W-360 is involved in an E2 function not yet known, for example, as a site for regulation of E2 activity.

Although this study has demonstrated residues necessary for $\mathrm{E} 2$ dimerization, the minimal sequence requirements remain unknown. It is possible that these se- quence requirements will include peptide segments throughout the carboxy-terminal 85 amino acids of E2. As demonstrated here, residues at both the amino terminus and carboxyl terminus of the 85-amino-acid domain are essential for proper folding and dimerization of E2.

The W-360 dimer contact occurs within a highly conserved block with the consensus [hydrophobic]-[S/T]-[S/ $\mathrm{T}]-\mathrm{T}-\mathrm{W}-[\mathrm{S} / \mathrm{H}]-\mathrm{W}$ (W-360 is underlined). Two proteins break the consensus at the last two positions (BPV-1 and $\mathrm{DPV})$; but, interestingly, both have an aromatic residue at position 6 of the sequence that may substitute for the lack of tryptophan at position 7. Chou-Fasman analyses (Chou and Fasman 1978) predict this block to also fold in the $\beta$ or extended configuration. Most of the conserved portions of the 85 -amino-acid DNA-binding/dimerization domain fall within five predicted $\beta$-strand segments (Fig. 7). Circular dichroism analysis demonstrated that E2/87 is $\sim 60 \% \beta$ conformation and $25 \% \alpha$-helix (unpublished). The G-333 to valine mutant (7 amino acids from the start of E2/87), defective for dimerization and folding of the DNA contact region, is at the predicted turn in the protein between two $\beta$ strands. The putative second $\beta$ strand consists of residues that we demonstrated to be necessary for DNA contact and is highly positively charged. The other $\beta$ strands, including the W-360 strand, are probably involved in dimer interactions and folding, perhaps as a $\beta$-barrel structure. A model involving $W-360$ and surrounding residues might envision the two $\beta$ strands aligned in an antiparallel fashion, with W-360 side chains closely aligned. Studies to determine the precise dimensions of the E2 DNA contact and dimerization motifs are in progress.

\section{Materials and methods}

\section{E2 mutagenesis}

BPV E2 was subcloned into M13 mp18 DNA from the yeast expression vector pYE2 (Morrissey et al. 1989) after the BamHI site at nucleotide 4450 was converted to Sall. Chemical mutagenesis was performed as described by Myers et al. (1985) with minor modifications. Twenty micrograms of single-stranded $\mathrm{mpl} 8$ containing the $\mathrm{E} 2$ gene was treated with $1.3 \mathrm{mM}$ potassium permanganate or $12 \mathrm{M}$ formic acid at $25^{\circ} \mathrm{C}$ for $10 \mathrm{~min}$ and neutralized with $2.5 \mathrm{M}$ sodium acetate $(\mathrm{pH} 7.0)$. Synthetic oligonucleotides positioned $3^{\prime}$ to the BstXI site at nucleotide 3881 were annealed and extended by avian myeloblastosis virus reverse transcriptase (Life Sciences, Inc.) or Sequenase 2.0 (U.S. Biochemical). The extension products were digested with KpnI and BstXI, and the 426-bp E2 fragments were subcloned into the wild-type background in pYE $2(2 \mu, U R A-3)$. This pool of mutagenized E2 was transformed into the yeast strain BGW1-7A containing a yeast reporter plasmid pBY- $4(2 \mu, L E U-2)$ containing four E2-binding sites upstream of the $l a c Z$ gene (Morrissey et al. 1989). Transformants were grown on selective medium with $2 \%$ glucose and replica-plated onto selective medium containing $2 \%$ galactose and $0.004 \% \mathrm{X}$-gal. Light blue or white colonies were analyzed for expression of full-length $\mathrm{E} 2$ proteins by immunoblot using rabbit antisera (Androphy et al. 1987); and after this confirmation, E2 mutants were isolated by yeast DNA miniprep and transformation into $E$. coli DH5 $\alpha$. Bacteria were plated on ampicillin X-gal plates, and the lacZ construct was excluded by its blue color. For site-directed mutagenesis of cys- 
teine-340, its TGC codon was changed to CGC (Kunkel et al. 1987). All E2 mutations were confirmed by DNA sequencing of both strands using flanking oligonucleotides.

\section{Expression of E2 proteins}

Yeast was cultured in minimal medium containing $2 \%$ galactose, pelleted, washed, resuspended, and disrupted by vigorous vortexing with acid-washed glass beads in two volumes of cold extraction buffer [200 mM Tris- $\mathrm{HCl}$ at $\mathrm{pH} 8.0,400 \mathrm{mM}\left(\mathrm{NH}_{4}\right)_{2}$ $\mathrm{SO}_{4}, 10 \mathrm{mM} \mathrm{MgCl}, 1 \mathrm{~mm}$ EDTA, $1 \mathrm{~mm}$ DTT, $10 \%$ glycerol with protease inhibitors, $1 \mathrm{mM}$ PMSF, $0.1 \mathrm{mg} / \mathrm{ml}$ of tosyl lysine chloromethyl ketone, $3 \mu \mathrm{M}$ pepstatin, $3 \mu \mathrm{M}$ leupeptin, and $5 \mathrm{~mm}$ benzamidine- $\mathrm{HCl}$. Debris was pelleted, and the supernatant was spun at $13000 \mathrm{~g}$ for $1 \mathrm{hr}$ at $4^{\circ} \mathrm{C}$. The supernatant was made $50 \%$ with saturated $\left(\mathrm{NH}_{4}\right)_{2} \mathrm{SO}_{4}$ and incubated on ice for $15 \mathrm{~min}$. Precipitated proteins were collected by centrifugation at $13000 \mathrm{~g}$ for $10 \mathrm{~min}$ at $4^{\circ} \mathrm{C}$ and dissolved in solubilization buffer $125 \mathrm{~mm}$ Tris-Cl at pH 8.0, 2 mM EDTA, 20\% glycerol, 1 mM DTT) containing the protease inhibitor cocktail.

Carboxy-terminal 127-amino-acid E2 polypeptides were expressed in the expression vector pET-8C (Studier et al. 1990) after creation of a $\mathrm{KpnI}$ site immediately $3^{\prime}$ to the $\mathrm{NcoI}$ cloning site and resulting in the addition of 2 amino acids, methionine and valine. The wild-type E2 reading frame from residue 286410 was inserted (KpnI-BamHI) to form pET-8C-E2-127. Mutant E2 genes were transferred into pET-8C-E2-127 as KpnI$B s t X I$ fragments. All constructs were transformed into the expression host E. coli strain BL21(DE3) pLYS S (Studier et al. 1990). After induction and freeze-thaw lysis in $20 \mathrm{mM}$ MES (pH 6.0) or $25 \mathrm{~mm}$ Tris- $\mathrm{HCl}(\mathrm{pH} 7.5)$ with 0.1 mM EDTA, 2 mM DTT, cell debris and insoluble proteins were removed by centrifugation. For further purification, E2 proteins were loaded onto 0.2 $\mathrm{ml}$ of Fast flow S-Sepharose (Pharmacia) pre-equilibrated in MES buffer, and eluted with $20 \mathrm{mM}$ MES (pH 6.0), $600 \mathrm{mM} \mathrm{NaCl}$, $5 \mathrm{mM}$ DTT, $1 \mathrm{mM}$ EDTA, 10\% glycerol, $1 \mathrm{mM}$ PMSF, $1 \mu \mathrm{M}$ pepstatin, $2 \mu \mathrm{g} / \mathrm{ml}$ of leupeptin, and $2 \mu \mathrm{g} / \mathrm{ml}$ of aprotinin. The quantity of $\mathrm{E} 2$ protein in the eluate was estimated by immunoblot. Purification of the E2/87 protein (Monini et al. 1991) was identical except cells were disrupted by French press. Peak fractions from S-Sepharose $(600 \mathrm{~mm} \mathrm{NaCl})$ were loaded directly onto a P-60 (Bio-Rad) gel filtration column equilibrated in GF-B with peak fractions $>95 \%$ pure. N6405 cells harboring pCOE $2 /$ 143 were grown at $30^{\circ} \mathrm{C}$ and induced at $42^{\circ} \mathrm{C}$. Cells were pelleted for $30 \mathrm{~min}$ at $4000 \mathrm{rpm}$, resuspended in $25 \mathrm{~mm}$ Tris $/ \mathrm{pH}$ $7.51,2 \mathrm{~mm}$ DTT, lysed by two passages through a French press at $10,000 \mathrm{psi}$, and clarified by centrifugation. Lysates were applied to a Fast flow S-Sepharose column equilibrated in $20 \mathrm{~mm}$ MES (pH 6.2). The column was washed with $20 \mathrm{mM}$ MES (pH 6.2) and step-eluted with $20 \mathrm{~mm}$ MES (pH 6.2), $5 \mathrm{~mm}$ DTT, and $0.1 \mathrm{~mm}$ EDTA, with peak fractions as analyzed by SDS-PAGE $(500-600$ $\mathrm{mM} \mathrm{NaCl}$ ) pooled. After 10 -fold dilution with $20 \mathrm{mM}$ Tris (pH 7.5), $5 \mathrm{~mm}$ DTT, the protein was loaded onto a Fast flow Q-Sepharose (Pharmacia) column equilibrated in $20 \mathrm{~mm}$ Tris (pH 7.5). The Q-Sepharose column was step eluted, and peak fractions $(100-150 \mathrm{mM} \mathrm{NaCl})$ were pooled and applied to a P-150 (Bio-Rad) gel-filtration column equilibrated in $10 \mathrm{mM}$ HEPES (pH 7.0), $50 \mathrm{~mm} \mathrm{NaCl}, 2 \mathrm{~mm}$ DTT, and $0.1 \mathrm{~mm}$ EDTA. Peak gel-filtration fractions contained $>95 \%$ pure E2/143. Protein concentrations were determined by Bradford-based Bio-Rad protein assay according to instructions and standardized with BSA.

\section{DNA-binding and dimerization assays}

EMSA was performed as in Monini et al. (1991). For dimerization analyses, yeast or bacterial extracts were exposed to 254 nm UV light $\left(8 \times 10^{4} \mu \mathrm{J}\right)$ in a Stratalinker (Stratagene), heated to $70^{\circ} \mathrm{C}$ in SDS sample buffer (Laemmli 1970), and separated on SDS-acrylamide gels. DSS (Pierce) cross-linking was performed in $50 \mathrm{~mm} \mathrm{Na}_{3} \mathrm{PO}_{4}$ (pH 7.5), $150 \mathrm{~mm} \mathrm{NaCl}, 2 \mathrm{~mm} \mathrm{DTT}$, and 0.1 mM EDTA with $0.5 \mathrm{mM}$ DSS at $25^{\circ} \mathrm{C}$ for $15 \mathrm{~min}$. Cross-linked samples were processed immediately for electrophoresis by addition of SDS sample buffer and heating at $70^{\circ} \mathrm{C}$ for $10 \mathrm{~min}$.

\section{Protein cleavage and sequencing}

Endo-Lys (Boehringer Mannheim) cleavage of UV cross-linked protein was performed with a $1: 20(\mathrm{wt} / \mathrm{wt})$ ratio of protease to protein for $16 \mathrm{hr}$ at $37^{\circ} \mathrm{C}$ in PBS $\left(50 \mathrm{mM} \mathrm{Na}{ }_{3} \mathrm{PO}_{4}(\mathrm{pH} 7.5), 150\right.$ $\mathrm{mM} \mathrm{NaCl}$ ) with $1 \mathrm{~mm} \mathrm{DTT}, 0.1 \mathrm{~mm}$ EDTA, and $5 \mathrm{M}$ urea. Fresh protease was added after $12 \mathrm{hr}$ of incubation. Cleavage products were alkylated with iodoacetic acid, separated by SDS-PAGE, and electroblotted to Immobilon P (Millipore). The membrane was stained with Coomassie blue and destained, and selected bands were excised for Edman sequencing. Samples were sequenced in an Applied Biosystems 470A gas phase sequencer with on-line PTH amino acid analysis. Hydroxylamine cleavages were performed as described (Saris et al. 1983) on gel slices excised from SDS-PAGE separations of UV cross-linked E2 proteins. After in situ cleavage, gel slices were placed in the well of a second SDS gel, and cleavage products were immunoblotted and detected with $\mathrm{mAb}$ B202.

\section{Acknowledgments}

We thank the members of our laboratories, S. Meredith and B. Schaffhausen for discussions, R. Myers for advice on chemical mutagenesis, F. Studier for the pET vectors and pLysS host, P. Chow for assistance with protein sequencing, L.L. Chen for developing the DSS cross-linking assay, J. Thulin for technical assistance, J. Barsoum for critical review, and S. Haverstock for preparation of this manuscript. This work was supported by the National Institutes of Health (NIH) (P01 CA 24530) and the Whitaker Health Sciences Foundation (E.J.A.), the Howard Hughes Medical Institute (L.A.L.), and NIH grant GM 02781 (S.R.G.). E.J.A. is supported by an American Cancer Society Faculty Research Award.

The publication costs of this article were defrayed in part by payment of page charges. This article must therefore be hereby marked "advertisement" in accordance with 18 USC section 1734 solely to indicate this fact.

\section{References}

Androphy, E.J., D.R. Lowy, and J.T. Schiller. 1987. Bovine papillomavirus E2 trans-activating gene product binds to specific sites in papillomavirus DNA. Nature 325: 70-73.

Bornstein, P. and G. Balian. 1977. Cleavage at asn-gly bonds with hydroxylamine. Methods Enzymol. 47: 132-145.

Breg, J.N., J.H. van Opheusden, M.J. Burgering, R. Boelens, and R. Kaptein. 1990. Structure of arc repressor in solution: Evidence for a family of beta-sheet DNA-binding proteins. $\mathrm{Na}$ ture 346: 586-589.

Chou, P.Y. and G.D. Fasman. 1978. Predictions of the secondary structure of proteins from their amino acid sequence. $A d v$. Enzymol. 47: 145-148.

Dostatni, N., F. Thierry, and M. Yaniv. 1988. A dimer of BPV-1 E2 containing a protease resistant core interacts with its DNA target. EMBO J. 7: 3807-3816.

Garnier, I., D.J. Osguthorpe, and B. Robson. 1978. Analysis of the accuracy and implications of simple methods for predicting the secondary structure of globular proteins. J. Mol. Biol. 
120: $97-120$.

Giri, I. and M. Yaniv. 1988. Structural and mutational analysis of E2 trans-activating proteins of papillomaviruses reveals three distinct functional domains. EMBO J. 7: 2823-2829.

Gius, D., S. Grossman, M.A. Bedell, and L.A. Laimins. 1988. Inducible and constitutive enhancer domains in the noncoding region of human papillomavirus type 18. I. Virol. 62: 665-672.

Grossweiner, L.I., G.W. Swenson, and E.F. Zwicher. 1963. Photochemical generation of the hydrated electron. Science 141: 805-806.

Harrison, S.M., K.L. Gearing, S.Y. Kim, A.J. Kingsman, and S.M. Kingsman. 1987. Multiple cis-active elements in the long control region of bovine papillomavirus type 1 (BPV-1). Nucleic Acids Res. 15: 10267-10284.

Haugen, T.H., T.P. Cripe, G.D. Ginder, M. Karin, and L.P. Turek. 1987. Trans-activation of an upstream early gene promoter of bovine papilloma virus-1 by a product of the viral E2 gene. EMBO I. 6: 145-152.

Haugen, T.H., L.P. Turek, F.M. Mercurio, T.P. Cripe, B.J. Olson, R.D. Anderson, D. Seidl, M. Karin, and J. Schiller. 1988. Sequence-specific and general transcriptional activation by the bovine papillomavirus-1 E2 trans-activator require an $\mathrm{N}$-terminal amphipathic helix-containing E2 domain. EMBO $J$. 7: 4245-4253

Hawley-Nelson, P., E.J. Androphy, D.R. Lowy, and J.T. Schiller. 1988. The specific DNA recognition sequence of the bovine papillomavirus E2 protein is an E2-dependent enhancer. EMBO J. 7: 525-531.

Hirochika, H., T.R. Broker, and L.T. Chow. 1987. Enhancers and trans-acting E2 transcriptional factors of papillomaviruses. $J$. Virol. 61: 2599-2606.

Hubbert, N., J.T. Schiller, D.R. Lowy, and E.J. Androphy. 1988. Bovine papilloma virus-transformed cells contain multiple E2 proteins. Proc. Natl. Acad. Sci. 85: 5864-5868.

Knight, J., R. Li, and M. Botchan. 1991. The activation domain of the bovine papillomavirus E2 protein mediates association of DNA-bound dimers to form DNA loops. Proc. Natl. Acad. Sci. 88: 3204-3208.

Kunkel, J.T., D. Roberts, and R.A. Zakour. 1987. Rapid and efficient site-specific mutagenesis without phenotypic selection. Methods Enzymol. 154: 367-382.

Laemmli, U.K. 1970. Cleavage of structural proteins during the assembly of the head of bacteriophage T4. Nature 227: 680 685.

Lambert, P.F., N. Dostatni, A.A. McBride, M. Yaniv, P.M. Howley, and B. Arcangioli. 1989. Functional analysis of the papilloma virus E2 trans-activator in Saccharomyces cerevisiae. Genes \& Dev. 3: 38-48.

Landschulz, W.H., P.F. Johnson, and S.L. McKnight. 1988. The leucine zipper: A hypothetical structure common to a new class of DNA binding proteins. Science 240: 1759-1764.

Lehrer, S.S. and G.D. Fasman. 1967. Ultraviolet irradiation effects in poly-L-tyrosine and model compounds. Identification of bityrosine as a photoproduct. Biochemistry 6: 757767.

Li, R., J. Knight, G. Bream, A. Stenlund, and M. Botchan. 1989. Specific recognition nucleotides and their DNA context determine the affinity of $\mathrm{E} 2$ protein for 17 binding sites in the BPV-1 genome. Genes \& Dev. 3: 510-526.

Malenick, D.A. and S.R. Anderson. 1987. Dityrosine formation in calmodulin. Biochemistry 26: 695-704.

McBride, A.A., R. Schlegel, and P.M. Howley. 1988. The carboxy-terminal domain shared by the bovine papillomavirus E2 transactivator and repressor proteins contains a specific DNA binding activity. EMBO $1.7: 533-539$.
McBride, A.A., J.C. Byrne, and P.M. Howley. 1989. E2 polypeptides encoded by bovine papillomavirus type 1 form dimers through the common carboxy-terminal domain: Transactivation is mediated by the conserved amino-terminal domain. Proc. Natl. Acad. Sci. 86: 510-514.

Mitchell, P.J. and R. Tjian. 1989. Transcriptional regulation in mammalian cells by sequence specific DNA binding proteins. Science 245: 371-378.

Mohr, I.J., R. Clark, S. Sun, E.J. Androphy, P. MacPherson, and M.R. Botchan. 1990. Targeting the El replication protein to the papillomavirus origin of replication by complex formation with the E2 transactivator. Science 250: 1694-1699.

Monini, P., S.R. Grossman, B. Pepinsky, E.J. Androphy, and L.A. Laimins. 1991. Cooperative binding of the E2 protein of bovine papillomavirus to adjacent E2-responsive sequences. $J$. Virol. 65: 2124-2130.

Morrissey, L.C., J. Barsoum, and E.J. Androphy. 1989. Trans activation by the bovine papillomavirus E2 protein in Saccharomyces cerevisiae. J. Virol. 63: 4422-4425.

Moskaluk, C. and D. Bastia. 1988. Interaction of the bovine papillomavirus type 1 E2 transcriptional control protein with the viral enhancer: Purification of the DNA-binding domain and analysis of its contact points with DNA. J. Virol. 62: 1925-1931.

- 1989. The bovine papillomavirus type 1 transcriptional activator E2 protein binds to its DNA recognition sequence as a dimer. Virology 169: 236-238.

Myers, R.M., L.S. Lerman, and T. Maniatis. 1985. A general method for saturation mutagenesis of cloned DNA fragments. Science 229: 242-246.

Ptashne, M. 1988. How eukaryotic transcriptional activators work. Nature 335: 683-689.

Rafferty, J.B., W.S. Somers, I. Saint Girons, and S.E. Phillips. 1989. Three-dimensional crystal structures of Escherichia coli met repressor with and without corepressor. Nature 341: 705-710.

Saris, C.J.M., J.V. Eenbergen, B.G. Jenks, and H.P.J. Bloemers. 1983. Hydroxylamine cleavage of proteins in polyacrylamide gels. Anal. Biochem. 132: 54-67.

Sousa, R., N. Dostatni, and M. Yaniv. 1990. Control of papillomavirus gene expression. Biochim. Biophys. Acta 1032: 1937.

Spalholz, B.A., Y.C. Yang, and P.M. Howley. 1985. Transactivation of a bovine papilloma virus transcriptional regulatory element by the E2 gene product. Cell 42: 183-191.

Spalholz, B.A., P.F. Lambert, C.L. Yee, and P.M. Howley. 1987. Bovine papillomavirus transcriptional regulation: Localization of the E2-responsive elements of the long control region. J. Virol. 61: 2128-2137.

Stanway, C.A., M.P. Sowden, L.E. Wilson, A.J. Kingsman, and S.M. Kingsman. 1989. Efficient activation of transcription in yeast by the BPV1 E2 protein. Nucleic Acids Res. 17: 21872196.

Studier, F.W., A.H. Rosenberg, J.J. Dunn, and J.W. Dubendorff. 1990. Use of T7 RNA polymerase to direct expression of cloned genes. Methods Enzymol. 185: 60-89.

Williams, T. and R. Tjian. 1991. Characterization of a dimerization motif in AP-2 and its function in heterologous DNAbinding proteins. Science 251: 1067-1070. 


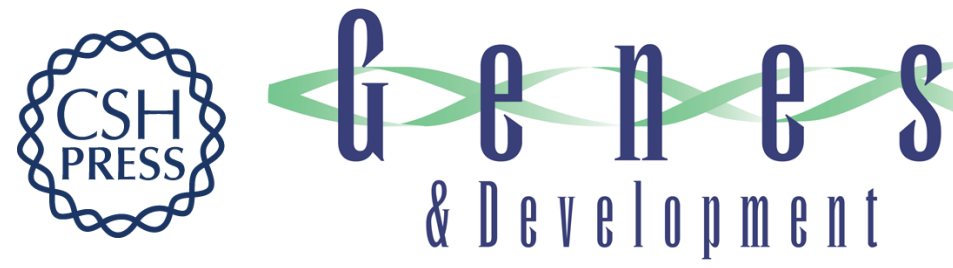

\section{Amino acids necessary for DNA contact and dimerization imply novel motifs in the papillomavirus E2 trans-activator.}

S S Prakash, S R Grossman, R B Pepinsky, et al.

Genes Dev. 1992, 6:

Access the most recent version at doi:10.1101/gad.6.1.105

References This article cites 41 articles, 17 of which can be accessed free at:

http://genesdev.cshlp.org/content/6/1/105.full.html\#ref-list-1

License

Email Alerting

Service

Receive free email alerts when new articles cite this article - sign up in the box at the top right corner of the article or click here.

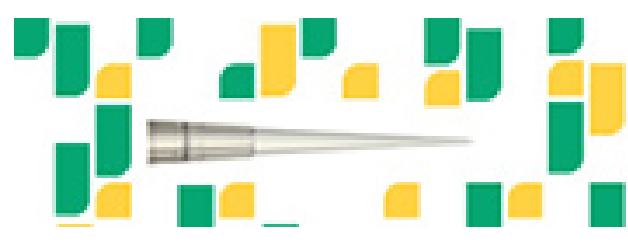

Focused on your science. 